\title{
Роль полиморфизма Q223R гена LEPR \\ как генетического предиктора синдрома перекрёста (синдром обструктивного апноэ/гипопноэ сна и хроническая обструктивная болезнь лёгких)
}

\author{
Зобова С.Н. ${ }^{1,2}$, Алексеева О.В. ${ }^{1}$, Шнайдер Н.А. ${ }^{1,3}$, Демко И.В. ${ }^{1}$, Прусова Т.И. ${ }^{1}$ \\ 1 - ФГБОУ ВО «Красноярский государственный медицинский университет имени профессора В.Ф. Войно-Ясенецкого» \\ Министерства здравоохранения Российской Федерации \\ Красноярск, Россия \\ 2 - ФГБНУ «Федеральный исследовательский центр «Красноярский научный центр Сибирского отделения Российской академии наук», \\ обособленное подразделение «Научно-исследовательский институт медицинских проблем Севера» \\ Красноярск, Россия \\ 3 - ФГБУ «Национальный медицинский исследовательский центр психиатрии и неврологии имени В.М. Бехтерева» \\ Санкт-Петербург, Россия
}

Коморбидность синдрома обструктивного апноэ/гипопноэ сна (СОАГС) и хронической обструктивной болезни лёгких (ХОБЛ) определяется как синдром перекрёста и является состоянием взаимного отягощения, характеризующегося ускоренным развитием легочной гипертензии и хронической дыхательной недостаточности, а также высоким риском внезапной смерти во сне. Вместе с тем, одним из наиболее значимых и независимых факторов риска развития СОАГС является ожирение. Целью исследования явилось выявление роли носительства однонуклеотидного полиморфного варианта (OHП) Q223R (rs1137101) гена LEPR в развитии синдрома перекрёста. Обследовано 134 человека (73,1\% мужчин и 26,9\% женщин) в возрасте 60 [53; 65] лет, из них 66 с диагнозом СОАГС, 30 - с диагнозом ХОБЛ и 38 с коморбидностью обеих форм патологии. Показано, что носительство как полиморфного аллеля $G$, так и генотипа $G G$ не является фактором риска развития СОАГС у пациентов с ХОБЛ $(p=0,92)$ и не коррелирует со степенью тяжести обеих нозологий, но статистически значимо ассоциировано с формированием ожирения 2 степени ( $<0,05)$. Полученные данные свидетельствуют о том, что среди жителей Красноярского края исследование OHП Q223R гена LEPR не может быть использовано в качестве генетического предиктора формирования синдрома перекрёста.

Ключевые слова: синдром обструктивного апноэ/гипопноэ сна, хроническая обструктивная болезнь лёгких, синдром перекрёста, однонуклеотидный полиморфный вариант, ген рецептора лептина.

Для цитирования: Зобова С.Н., Алексеева О.В., Шнайдер Н.А., Демко И.В., Прусова Т.И. Роль полиморфизма Q223R гена LEPR как генетического предиктора синдрома перекрёста (синдром обструктивного апноэ/гипопноэ сна и хроническая обструктивная болезнь лёгких). Медицинская генетика 2020; 19(1): 46-54

DOI: $10.25557 / 2073-7998.2020 .01 .46-54$

Автор для корреспонденции: Алексеева Ольга Владимировна; e-mail: aleksvrach@mail.ru Финансирование отсутствует.

Конфликт интересов. Авторы декларируют отсутствие конфликта интересов.

Поступила: 15.01.2020.

\section{Role Q223R polymorphism of LEPR gene as genetic predictor for overlap syndrome (obstructive sleep apnea / hypopnea syndrome and chronic obstructive pulmonary disease)}

\author{
Zobova S.N. ${ }^{1,2}$, Alekseeva O.V. ${ }^{1}$, Shnayder N.A. ${ }^{1,3}$, Demko I.V. ${ }^{1}$, Prusova T.I. ${ }^{1}$ \\ 1 - Krasnoyarsk State Medical University n.a. V.F. Voyno-Yasenetsky \\ Krasnoyarsk, Russia \\ 2 - Scientific Research Institute of Medical Problems of the North, Krasnoyarsk Research Center, Siberian Division of Russian Academy of Sciences \\ Krasnoyarsk, Russia \\ 3 - National Research Medical Center for Psychiatry and Neurology n.a. V.M. Bekhterev \\ Saint Petersburg, Russia
}

Comorbidity of obstructive sleep apnea / hypopnea syndrome (OSAHS) and chronic obstructive pulmonary disease (COPD) is defined as overlap syndrome and is a state of mutual aggravation characterized by an accelerated development of pulmonary hypertension and chronic respiratory failure, as well as a high risk of sudden death in sleep. At the same time, obesity is one of the most significant and independent risk factors for the development of OSAHS. The aim of the study was to identify the role of the leptin 
receptor gene LEPR single nucleotide polymorphism (SNP) Q223R (rs1137101) in the development of overlap syndrome. A total of 134 people (73,1\% of men and 26,9\% of women) aged 60 [53;65] years were examined, 66 of them with OSAHS, 30 patients with a diagnosis of COPD, and 38 with comorbidity of both forms of pathology. It was shown that the carriage of both the polymorphic $G$ allele and the $G G$ genotype is not a risk factor for the development of OSAHS in patients with COPD $(p=0,92)$ and does not correlate with the severity of both nosologies, but is statistically significantly associated with the formation of obesity 2 degrees $(p<$ 0,05). The findings suggest that among the residents of the Krasnoyarsk Territory, the study of SNP Q223R of the LEPR gene cannot be used as a genetic predictor of the formation of overlap syndrome.

Key words: obstructive sleep apnea / hypopnea syndrome, chronic obstructive pulmonary disease, overlap syndrome, single nucleotide polymorphism, leptin receptor gene.

For citation: Zobova S.N., Alekseeva O.V., Shnayder N.A., Demko I.V., Prusova T.I. Role Q223R polymorphism of $L E P R$ gene as genetic predictor for overlap syndrome (obstructive sleep apnea / hypopnea syndrome and chronic obstructive pulmonary disease). Medical genetics 2020; 19(1): 46-54. [In Rus] DOI: $10.25557 / 2073-7998.2020 .01 .46-54$

Corresponding author. Alekseeva Olga, e-mail: aleksvrach@mail.ru Funding is absent.

Conflict of interest. The authors declare no conflict of interest.

Accepted: 15.01.2020.

\section{Введение}

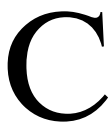

индром обструктивного апноэ/гипопноэ сна (СОАГС) представляет собой состояние, при котором имеют место повторяющиеся эпизоды прекращения дыхания во время сна вследствие закрытия просвета верхних дыхательных путей при сохранённых движениях дыхательной мускулатуры, в результате чего развиваются десатурация, грубая фрагментация сна и дневная гиперсомния [1]. Распространенность СОАГС составляет 5-7\% от всего населения старше 30 лет. Тяжелыми формами заболевания страдают около 1-2\% из указанной группы лиц [2]. СОАГС является многофакторным заболеванием, в формирование которого вносят вклад как генетические, так и средовые факторы (особенности питания, качество ночного сна, наличие вредных привычек). В качестве возможных генов-кандидатов, ответственных за формирование СОАГС, рассматриваются ген $L E P$, кодирующий лептин - анорексигенный метаболический гормон, среди многочисленных эффектов которого на животных моделях отмечено влияние на рост лёгких, дыхание и даже архитектонику сна [3], ген $L E P R$, кодирующий рецепторы к лептину, ген $P P A R G$, кодирующий рецептор, активируемый пероксисомным пролифератором [4]. Особое место среди однонуклеотидных полиморфизмов (OHП) гена LEPR (W31X; A409E; W664R; H684P; Q223R; K109R; K656N и др.) занимает Q223R (rs1137101), приводящий к замене глутамина на аргинин в лептин-связывающем экстрацеллюлярном С-домене рецептора $[3,5]$ и ассоциированный с дислипидемией, ожирением и инсулинорезистентностью [3].

Известно, что ожирение является одним из наиболее значимых и независимых факторов риска развития апноэ сна, при этом многие исследователи выделяют
СОАГС и ожирение в отдельный промежуточный фенотип [6]. Воздействие ожирения на дыхание во сне реализуется несколькими путями. Жировая инфильтрация тканей глотки приводит к ухудшению эластичности ее стенок и снижению сократимости мышц-дилататоров верхних дыхательных путей. Увеличенный объем жировой ткани в парафарингеальных клетчаточных пространствах оказывает давление на глоточные стенки с наружной стороны, способствуя нарушению баланса сил, влияющих на величину просвета [7]. Кроме того, эпизоды апноэ, изменяя структуру сна, приводят к редукции глубоких стадий медленного сна и нарушению выработки инсулиноподобного фактора роста 1, опосредующего влияние соматотропного гормона, который в свою очередь играет роль в балансе между жировой и мышечной массой человеческого тела. Недостаток гормона роста у взрослого вызывает сдвиг к большему содержанию жировой массы по сравнению с мышечной, способствуя развитию абдоминального ожирения, что формирует своеобразный порочный круг [8].

Сочетание СОАГС с хронической обструктивной болезнью лёгких (ХОБЛ) определяется как синдром перекрёста и является состоянием взаимного отягощения, при котором отмечаются худшие показатели ночной гипоксемии и гиперкапнии, ускоренное развитие легочной гипертензии и хронической дыхательной недостаточности, учащение нарушений сердечного ритма и проводимости, а также высокий риск внезапной смерти во сне [9-11]. Поиск генетических предикторов развития СОАГС у больных с ХОБЛ является актуальной задачей, в особенности в условиях промышленного мегаполиса с высоким уровнем загрязнения атмосферного воздуха [12]. 
Целью исследования стало выявление роли носительства ОНП Q223R (rs1137101) гена LEPR, кодирующего рецептор лептина, в развитии СОАГС у больных с ХОБЛ.

В задачи исследования входили оценка частот носительства аллелей и генотипов ОНП Q223R гена $L E P R$ у пациентов с ХОБЛ, СОАГС и синдромом перекрёста, поиск генетических ассоциаций со степенью тяжести указанных нозологий, исследование генетических корреляций между частотой носительства Q223R и степенью ожирения у больных СОАГС, а также оценка вклада курения в формирование фенотипа исследуемых заболеваний.

\section{Пациенты и методы}

Проведение исследования было одобрено на заседании Локального этического комитета ГБОУ ВПО КрасГМУ им. проф. В.Ф. Войно-Ясенецкого Министерства здравоохранения Российской Федерации (протокол № 60/2015 от 28.01.2015). Все пациенты подписали информированное согласие на добровольное участие в исследовании, на забор биологического материала (кровь).

В исследовании принимали участие 134 человека $(73,1 \%(98 / 134)$ мужчин и $26,9 \%(36 / 134)$ женщин) в возрасте 60 [53; 65] лет (от 32 до 82 лет), из них 66 человек с диагнозом СОАГС, 30 человек с диагнозом ХОБЛ и 38 человек с коморбидностью обеих форм патологии (синдромом перекрёста). Диагностику синдрома перекрёста проводили с использованием методов кардиореспираторного, респираторного мониторирования и спирографии. Для респираторного мониторинга использовали приборы «ApneaLink» (ResMed Австралия) и «SOMNOcheck micro» (Weinman, Германия) c программным обеспечением «SomnoLab» производства Weinmann (Германия). Кардиореспираторное мониторирование с целью выявления апноэ сна проводили с помощью аппарата «Медиком МТД» (Россия). Степень тяжести СОАГС определяли согласно индексу апноэ/гипопноэ (ИАГ) - частоты эпизодов апноэ/гипопноэ в час, с учётом уровня сатурации. Индекс курильщика (ИК) рассчитывали по следующей формуле: количество сигарет, выкуриваемых в течение суток $\times$ стаж курения в годах)/20.

Выделение геномной ДНК осуществляли сорбционным методом из 0,1 мл взвеси лейкоцитов с использованием набора «ДНК-Сорб-В» (103-20, «АмплиПрайм», Россия) согласно инструкции производителя. Определение носительства ОНП rs1137101 $($ c.668A $>\mathrm{G})$ гена $L E P R$ осушествляли методом полимеразной цепной реакции в режиме реального време- ни (ПЦР-РВ) на аппарате «Rotor-Gene 6000» (Corbett Life Science, Австралия) с использованием технологии аллельной дискриминации ТаqМап и коммерчески доступных флюоресцентных зондов («Applied Biosystems», США). В состав буфера входили 2,5-кратная реакционная смесь, адаптированная для ПЦР-РВ, $25 \mathrm{MM} \mathrm{MgCl}$, $\mathrm{dd}_{2} \mathrm{O}$ (М-428, «Синтол», Россия). Амплификация была выполнена в объёме 25 мкл, содержащем 100 150 нг ДНК, по следующему протоколу: $95^{\circ} \mathrm{C}-10$ мин; $92^{\circ} \mathrm{C}-15$ c, $60^{\circ} \mathrm{C}-90$ с (50 циклов). В каждый эксперимент включали отрицательный контроль, где ДНКматрицу заменяли дистиллированной водой. Варианты генотипов ОНП rs1137101 были обозначены следующим образом: гомозиготный генотип - $A A$ (аденин/ аденин), гетерозиготный генотип - $A G$ (аденин/гуанин), гомозиготный генотип - $G G$ (гуанин/гуанин).

Статистический анализ проводили с использованием пакетов прикладных программ STATISTICA (версия 10.0). Значимость различий между количественными показателями независимых выборок оценивали по непараметрическому критерию Крускалла-Уоллиса. Распределение генотипов по исследуемому полиморфному аллельному варианту проверяли на соответствие равновесию Харди-Вайнберга (РХВ). При попарном сравнении частот аллелей и генотипов с помощью критерия хи-квадрат Пирсона $\left(\chi^{2}\right)$ использовали онлайнкалькулятор «Ген Эксперт», доступный по электронному адресу http://gen-exp.ru. Для анализа произвольных сопряжённых таблиц оценивался точный критерий Фишера. Риск развития СОАГС и ожирения оценивали в значениях показателя отношения шансов (ОШ, 95\% доверительный интервал (95\% ДИ)).

\section{Результаты}

При сравнении частоты носительства генотипов ОНП Q223R у пациентов с ХОБЛ, СОАГС и синдромом перекрёста статистически значимых межгрупповых различий выявлено не было $\left(\chi^{2}=0,816 ; p=0,937\right)$ (табл. 1). Распределение генотипов во всех диагностических группах соответствовало равновесию Харди-Вайнберга $\left(\chi^{2}=0,12, \mathrm{p}=0,73\right.$ у пациентов с ХОБЛ; $\chi^{2}=0,00, p=0,96$ у пациентов с СОАГС; $\chi^{2}=0,59$, $\mathrm{p}=0,44$ при синдроме перекрёста), что позволяет предполагать их стабильное носительство в последующих поколениях при соблюдении условий генетического равновесия.

Взаимосвязь между полом пациентов и генотипом отсутствовала как в общей выборке всех обследованных пациентов, так и внутри каждой диагностической группы. При этом среди лиц с генотипами $A G$ и $G G$ во всех группах сравнения мужчины встречались стати- 
стически значимо чаще $(\mathrm{p}=0,023$ и $\mathrm{p}=0,009$, соответственно) (табл. 1).

Частоты аллелей исследуемого полиморфного варианта также не имели значимых межгрупповых различий (табл. 2). Было показано, что носительство как полиморфного аллеля $G$ (ОШ 1,14; $95 \%$ ДИ 0,58 - 2,25; $\mathrm{p}=0,71)$, так и гомозиготного генотипа $G G(\mathrm{OШ} 0,95$;
$95 \%$ ДИ $0,33-2,71 ; \mathrm{p}=0,69)$ не являются факторами риска СОАГС у пациентов с ХОБЛ (табл. 2).

В настоящем исследовании нами проведён поиск генетических ассоциаций между частотой носительства OHП Q223R гена $L E P R$ и степенью ожирения у больных СОАГС (табл. 3, рис. 1). Выявлены статистически значимые различия между группами больных с 1 и 2 сте-

Таблица 1

Гендерные особенности частоты носительства генотипов полиморфизма rs1137101 (Q223R) гена рецептора лептина LEPR при ХОБЛ, СОАГС и коморбидности обеих форм патологии (ХОБЛ+СОАГС)

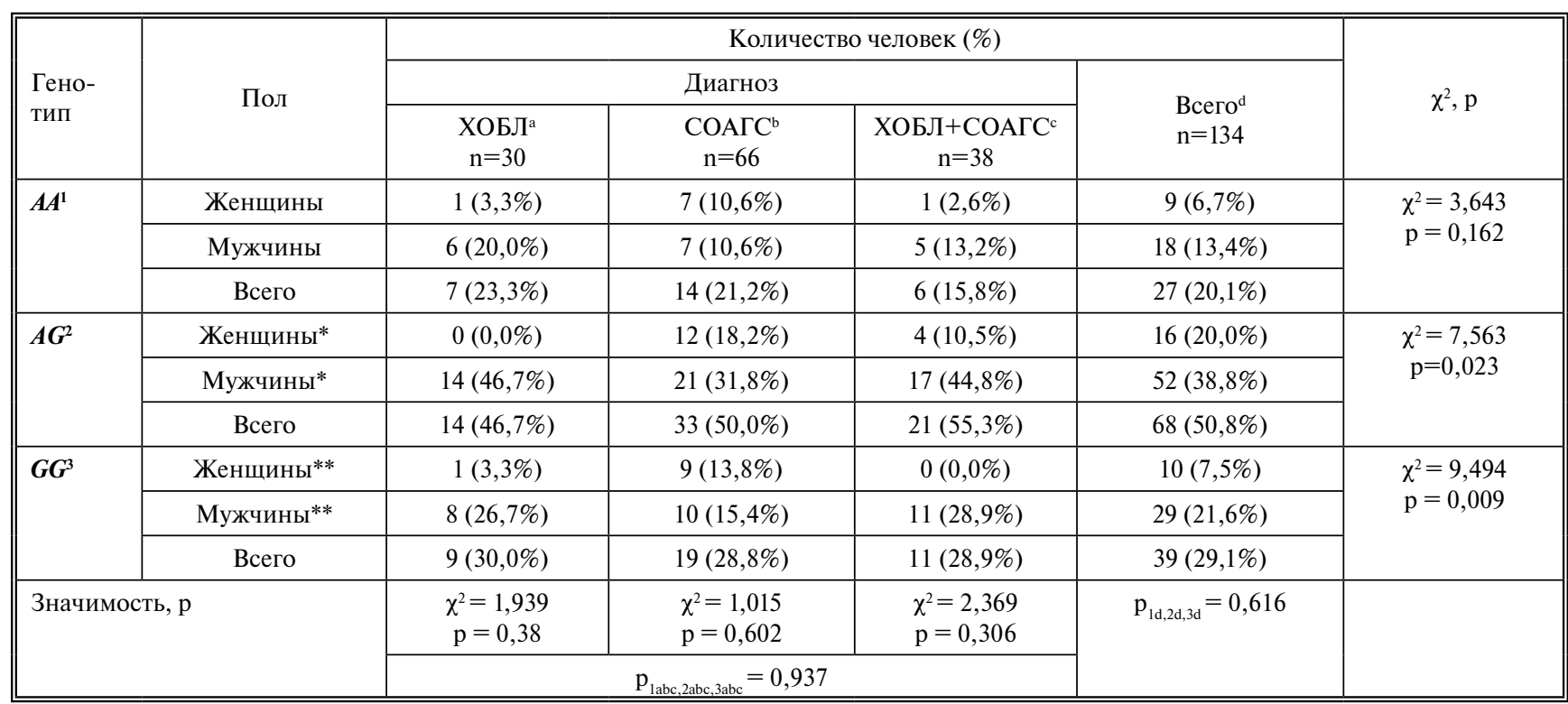

$*-p<0,05 ; *-p<0,01$.

Оценка отношения шансов развития СОАГС у пациентов с ХОБЛ и ХОБЛ у пациентов с СОАГС при использовании теста случай-контроль согласно мультипликативной и общей моделям наследования

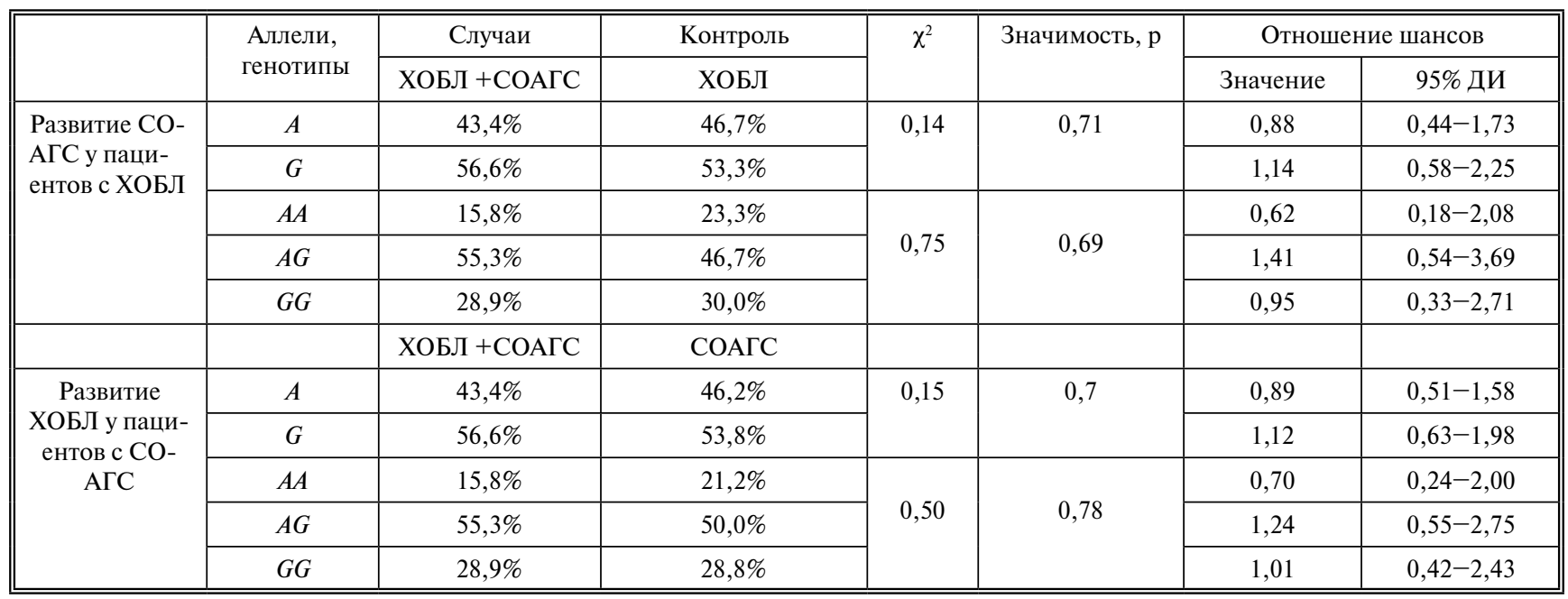


пенями ожирения, как по частоте носительства аллелей $\left(\chi^{2}=4,85 ; \mathrm{p}=0,03\right)$, так и по частоте носительства генотипов $\left(\chi^{2}=6,48 ; p=0,04\right)$ ОНП Q223R согласно мультипликативной и общей моделям наследования. Обе модели применимы, поскольку для обеих выборок выпол- няются условия РХВ (для 1 степени ожирения $\chi^{2}=0,09$, $\mathrm{p}=0,77$; для 2 степени ожирения $\left.\chi^{2}=2,8, \mathrm{p}=0,09\right)$. При этом ОШ для аллеля $A$ составило 0,35 (95\% ДИ 0,14 $0,90)$, а для аллеля $G-2,86(95 \%$ ДИ $1,11-7,38)$. Для гомозиготного генотипа $A A$ ОШ оказалось равным 0,53

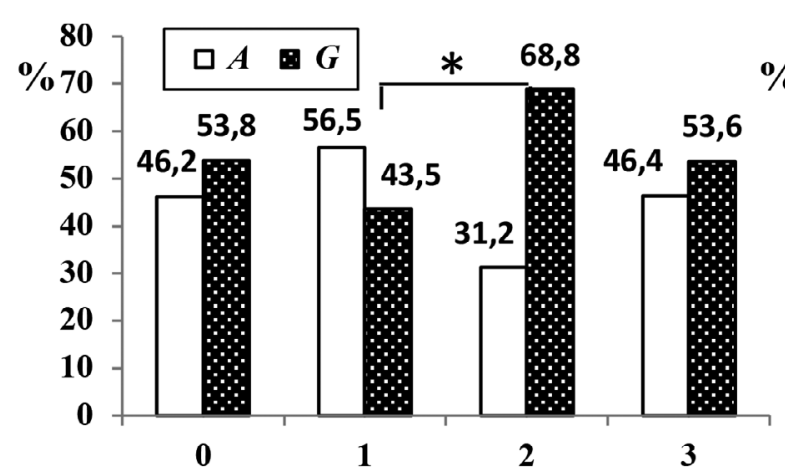

Степени ожирения

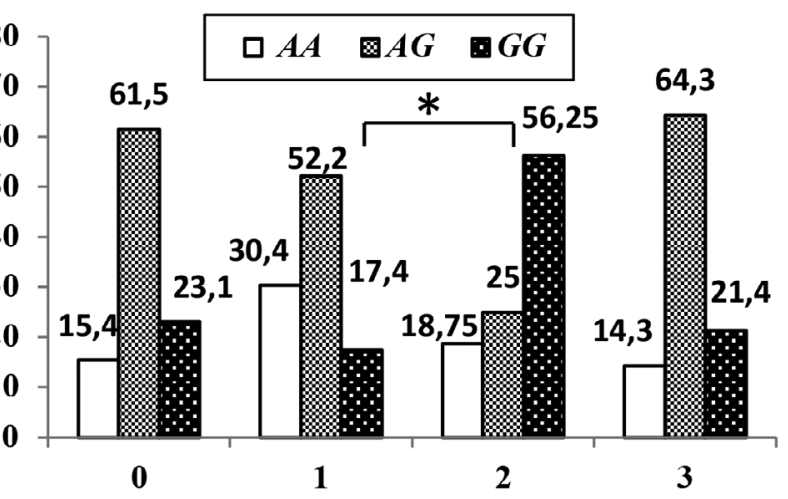

Степени ожирения

Рис. Частоты носительства аллелей (А) и генотипов (Б) полиморфизма Q223R гена LEPR в зависимости от степени ожирения согласно ИМT у пациентов с СОАГС.

* - статистическая значимость при $\mathrm{p}<0,05$.

таблича 3

Частота носительства аллелей и генотипов полиморфизма Q223R гена $L E P R$ В зависимости от степени ожирения при ХОБЛ, СОАГС и синдроме перекрёста (ХОБЛ+СОАГС).

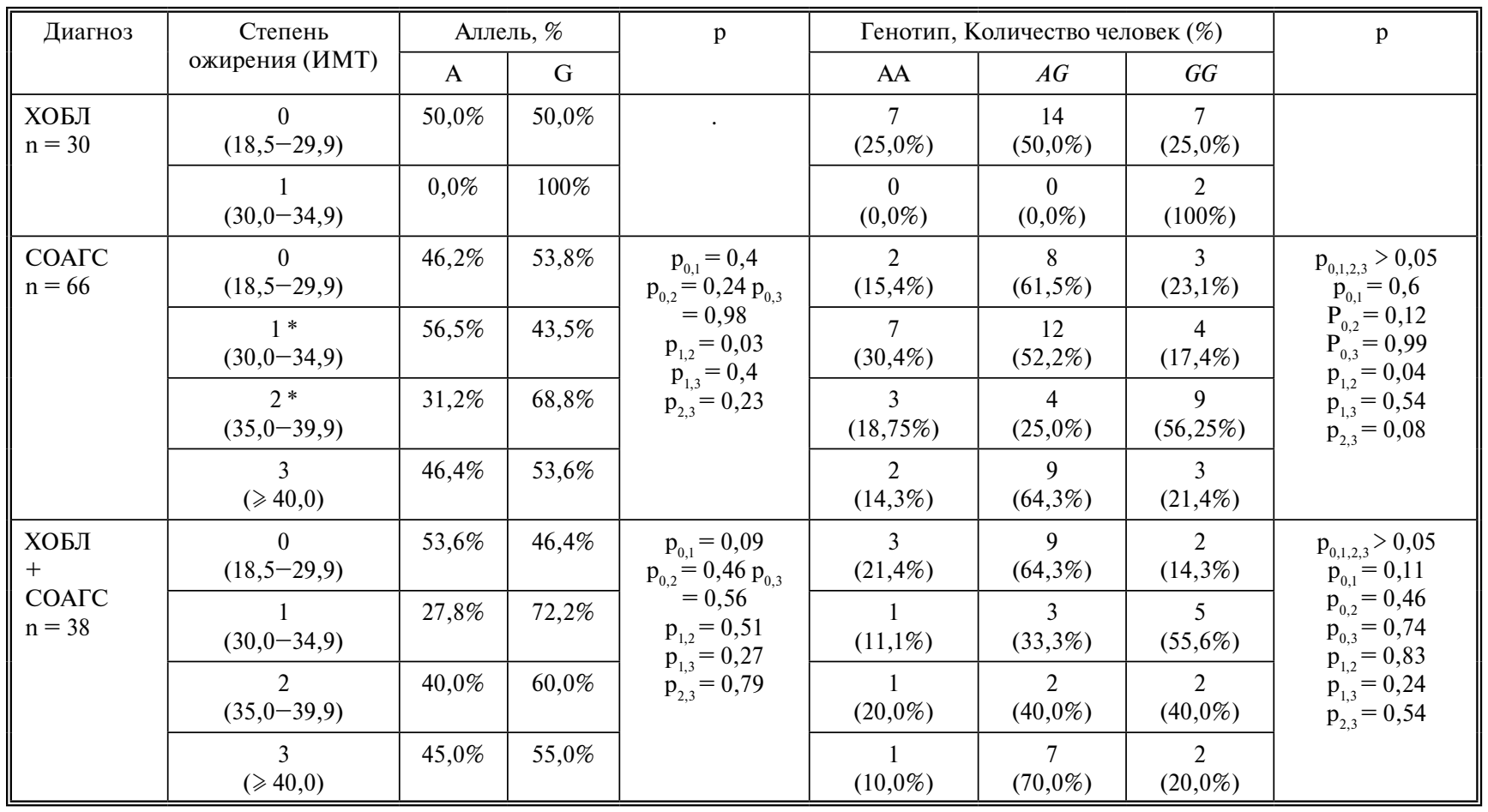

$*_{-} \mathrm{p}<0,05 ; *{ }^{*}-\mathrm{p}<0,01$. 
(95\% ДИ 0,11-2,46), для гетерозиготного генотипа $A G$ ОШ составило 0,31 (95\% ДИ 0,08-1,23), тогда как для гомозиготного генотипа $G G$ ОШ было определено как 6,11 (95\% ДИ 1,42-26,36). Таким образом, у лиц со 2 степенью ожирения аллель $G$ и генотип $G G$ встречались статистически значимо чаще и являлись факторами риска для развития данного фенотипа. При использовании точного критерия Фишера для оценки влияния фактора носительства гомозиготного генотипа $G G$ на развитие ожирения 2 степени была получена статистическая значимость $(\mathrm{p}=0,017)$.

Размер выборок пациентов с ХОБЛ после стратификации по степеням ожирения согласно ИМТ оказался недостаточен для проведения межгрупповых сравнений. При анализе частот аллелей и генотипов полиморфизма Q223R гена $L E P R$ у пациентов с синдромом перекрёста статистически значимых межгрупповых различий выявлено не было (табл. 3).

Показано, что между частотой носительства гомозиготного генотипа $G G$ и степенью ожирения согласно величине ИМТ у пациентов с СОАГС отсутствует корреляция (коэффициент корреляции Спирмена $\rho=0,00 ; \mathrm{p}<0,05)$, при этом установлено, что носительство полиморфизма Q223R не оказывает существен- ного влияния на формирование фенотипа ожирения 3 степени (табл. 3 , рис. 1).

Изучение ассоциации частоты носительства генотипов ОНП Q223R со степенью тяжести ХОБЛ не выявило статистически значимых межгрупповых различий, как среди пациентов с изолированной ХОБЛ, так и у лиц с синдромом перекрёста $\left(\chi^{2}=0,951 ; \mathrm{p}=0,918\right)$. Анализ общей выборки пациентов, включающей обе описанные группы, подтвердил полученные результаты $\left(\chi^{2}=3,108 ; p=0,54\right)$ (табл. 4).

При исследовании ассоциации частоты носительства генотипов ОНП Q223R со степенью тяжести СОАГС у больных в общей выборке пациентов, имеющих данный диагноз (изолированный СОАГС и синдром перекрёста, $\mathrm{n}=104)$, статистически значимых межгрупповых различий выявлено не было $\left(\chi^{2}=4,854\right.$; $\mathrm{p}=0,303)$ (табл. 5). Аналогичные данные были получены для пациентов с изолированным СОАГС $\left(\chi^{2}=6,369\right.$; $\mathrm{p}=0,174)$ и синдромом перекрёста $\left(\chi^{2}=3,897 ; \mathrm{p}=0,421\right)$. Следует отметить тенденцию к увеличению числа гетерозиготных носителей при 3 степени тяжести заболевания (табл. 5).

Поскольку и ХОБЛ, и СОАГС являются многофакторными заболеваниями, в формирование которых большой

Таблица 4

Ассоциация ОНП Q223R гена $L E P R$ со степенью тяжести ХОБЛ у больных изолированной ХОБЛ и синдромом перекрёста

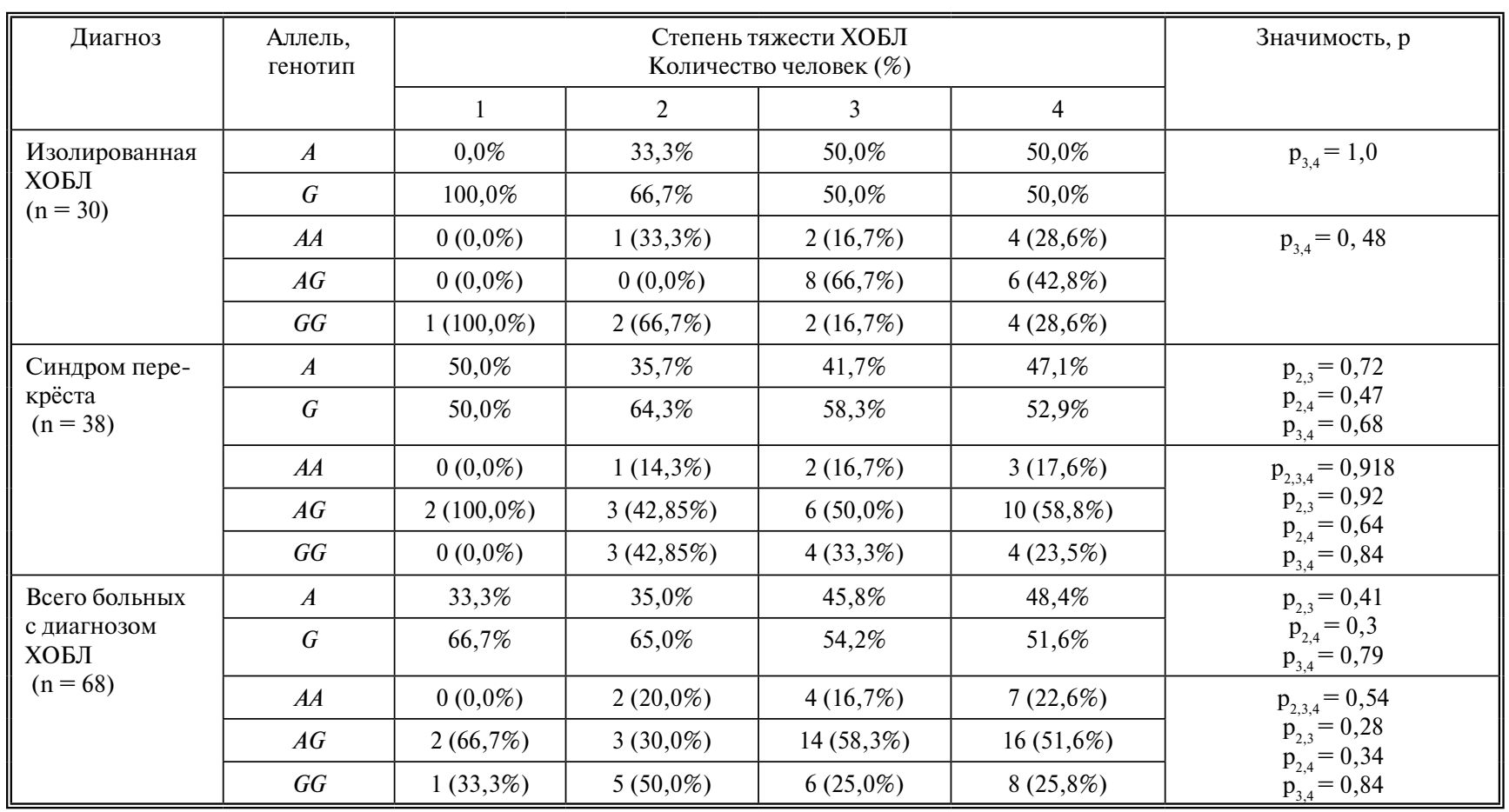


вклад вносят внешнесредовые факторы, такие как образ жизни и наличие вредных привычек, было предпринято сравнение количества курящих пациентов в каждой диагностической группе, имеющих неблагоприятный генотип, с учётом стажа курения и числа выкуриваемых сигарет - индекса курильщика (ИК) (табл. 6).

Наибольшее число курящих пациентов было выявлено среди больных с ХОБЛ $(80,0 \%)$ и синдромом перекрёста $(81,6 \%)$, наименьшее - среди пациентов с СОАГС $(34,8 \% ; \mathrm{p}<0,001)$. При стратификации по фактору носительства генотипа ОНП Q223R пациенты с ХОБЛ и синдромом перекрёста имели приблизительно равное число курильщиков среди носителей каждого генотипа ( $\mathrm{p}>0,05)$, при этом среди лиц, имеющих благоприятный генотип $A A$, свыше $80 \%$ составляли курящие. У пациентов с СОАГС наибольшее число курящих было обнаружено среди пациентов с генотипом $A G(\mathrm{p}=0,017)$. Можно предположить, что у лиц с ХОБЛ и синдромом перекрёста в формировании фенотипа заболевания основная роль принадлежала наличию вредной привычки.

Таблица 5

\section{Ассоциация OHП Q223R гена LEPR со степенью тяжести СОАГС у больных изолированным СОАГС и синдромом перекрёста}

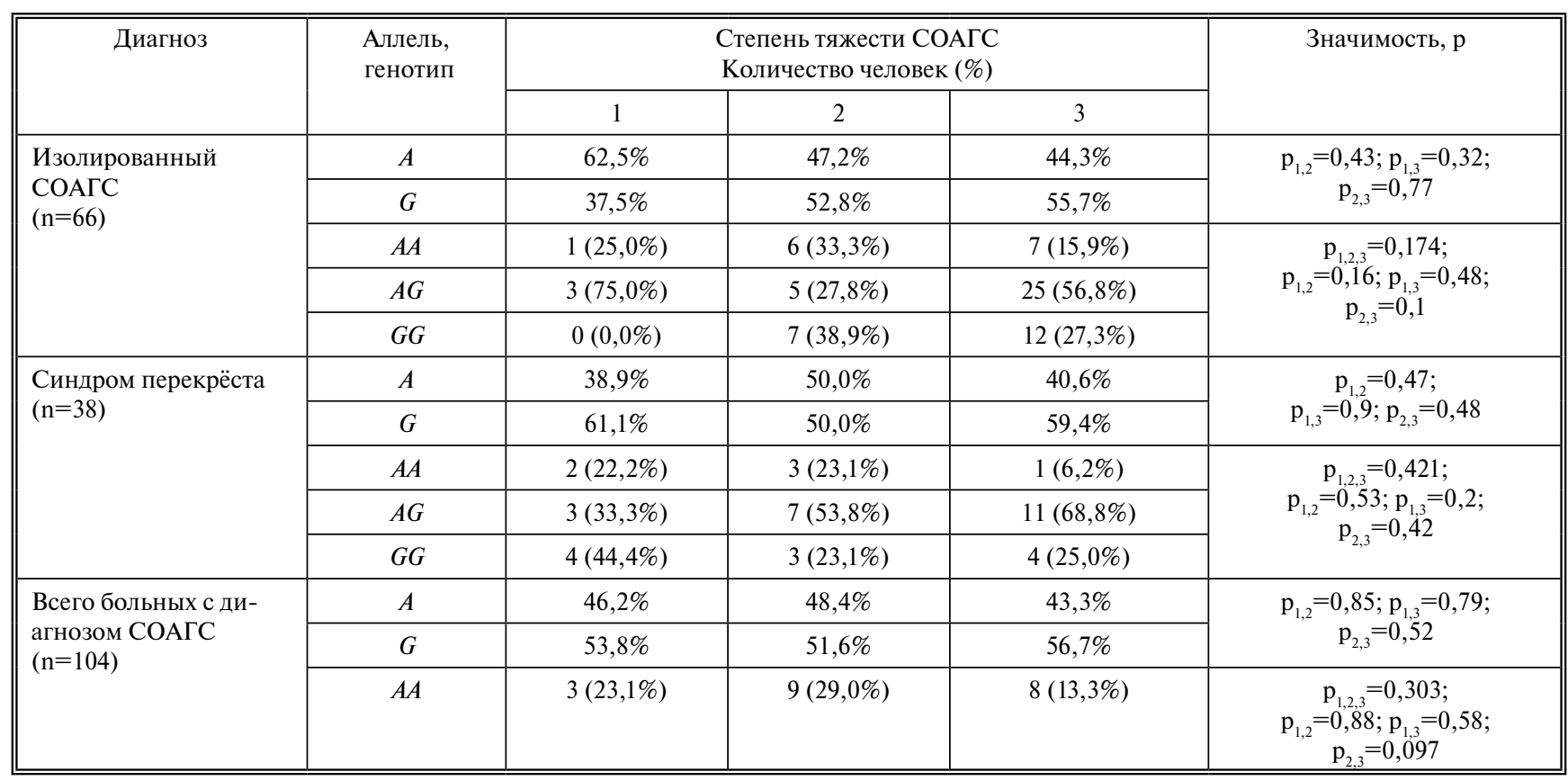

Таблица 6

Количество курящих пациентов и средний ИК среди больных с ХОБЛ, СОАГС и синдромом перекрёста в зависимости от генотипа OHП Q223R гена LEPR

\begin{tabular}{|c|c|c|c|c|c|}
\hline \multirow[t]{2}{*}{ Генотип } & \multicolumn{3}{|c|}{ Количество курящих пациентов: n (\%) } & \multirow{2}{*}{$\begin{array}{c}\text { Количество курящих в } \\
\text { группе: n (\%) }\end{array}$} & \multirow[t]{2}{*}{ Значимость, $\mathrm{p}$} \\
\hline & $A A(1)$ & $A G(2)$ & $G G(3)$ & & \\
\hline ХОБЛ $(\mathrm{n}=30)^{\mathrm{a}}$ & $6(85,7 \%)$ & $11(78,6 \%)$ & $7(77,8 \%)$ & $24(80,0 \%)$ & $\mathrm{p}_{1,2,3}=0,911$ \\
\hline СОАГС $(\mathrm{n}=66)^{\mathrm{b}}$ & $3(21,4 \%)$ & $17(51,5 \%)$ & $3(15,8 \%)$ & $23(34,8 \%)$ & $\mathrm{p}_{1,2,3}=0,017$ \\
\hline Синдром перекрёста $(\mathrm{n}=38)^{\mathrm{c}}$ & $5(83,3 \%)$ & $16(76,2 \%)$ & $10(90,9 \%)$ & $31(81,6 \%)$ & $\mathrm{p}_{1,2,3}=0,591$ \\
\hline Значимость, p & $\mathrm{p}_{\mathrm{a}, \mathrm{b} . \mathrm{c}}=0,005$ & $\mathrm{p}_{\mathrm{a}, \mathrm{b} . \mathrm{c}}=0,087$ & $\mathrm{p}_{\mathrm{a}, \mathrm{b} . \mathrm{c}}<0,001$ & $\mathrm{p}_{\mathrm{a}, \mathrm{b} . \mathrm{c}}<0,001$ & \\
\hline \multicolumn{6}{|c|}{ Индекс курильщика, M \pm SD } \\
\hline ХОБЛ $(\mathrm{n}=30)$ & $35,5 \pm 23,95$ & $37,64 \pm 21,98$ & $26,29 \pm 13,56$ & $33,79 \pm 20,19$ & $\mathrm{p}_{1,2,3}=0,603$ \\
\hline СОАГС $(n=66)$ & $30,0 \pm 13,23$ & $24,71 \pm 16,70$ & $22,67 \pm 26,39$ & $25,46 \pm 17,09$ & $\mathrm{p}_{1,2,3}=0,482$ \\
\hline Синдром перекрёста $(\mathrm{n}=38)$ & $52,4 \pm 18,74$ & $36,75 \pm 17,41$ & $31,5 \pm 8,18$ & $37,58 \pm 16,37$ & $\mathrm{p}_{1,2,3}=0,069$ \\
\hline Значимость, $\mathrm{p}$ & $\mathrm{p}_{\mathrm{a}, \mathrm{b} . \mathrm{c}}=0,238$ & $\mathrm{p}_{\mathrm{a}, \mathrm{b} . \mathrm{c}}=0,259$ & $\mathrm{p}_{\mathrm{a}, \mathrm{b} . \mathrm{c}}=0,504$ & $\mathrm{p}_{\mathrm{a}, \mathrm{b} . \mathrm{c}}=0,066$ & \\
\hline
\end{tabular}




\section{Обсуждение}

Литературные данные об ассоциации носительства полиморфного аллельного варианта rs1137101 и развития СОАГС весьма разноречивы и во многом зависят от этнической принадлежности изучаемой выборки. Исследование, проведённое польскими учёными на 179 европеоидах обоего пола (102 пациента с СОАГС и 77 здоровых волонтёров), продемонстрировало статистически значимую ассоциацию между гомо- и гетерозиготным носительством аллеля $G$ и развитием ожирения и СОАГС как в общей выборке обследуемых, так и у женщин. При этом среди пациентов с СОАГС наиболее высокие уровни общего холестерина и липопротеидов низкой плотности были отмечены у гомозигот $G G$ (несколько меньшие у гетерозигот $A G$ ) по сравнению с носителями генотипа $A A$ [13]. Вместе с тем, среди коренного населения Китая (хань) в сопоставимой выборке (130 больных СОАГС и 136 здоровых волонтёров) развитие СОАГС не было статистически значимо ассоциировано ни с носительством полиморфных вариантов гена лептина $L E P$ (тестированы образующие гаплотип ОНП rs4731426, rs11763517, rs10954173 и rs2071045), ни с носительством вариантов rs1137101 как в общей группе обследуемых, так и после стратификации по полу, массе тела и тяжести заболевания [14]. А у мужчин турецкой этнической группы носительство аллельного варианта rs 1137101 не только не ассоциировалось с развитием СОАГС, но даже статистически значимо коррелировало с более низкими показателями ИМТ и артериального давления [3].

При этом в доступных нам литературных источниках было показано отсутствие статистически значимых ассоциаций носительства аллельного варианта rs1137101 с худшими показателями функции внешнего дыхания и развитием ХОБЛ по сравнению со здоровыми волонтёрами [15], что позволило выделить пациентов с ХОБЛ в качестве группы контроля. Можно предположить, что у лиц с ХОБЛ в формировании фенотипа заболевания основная роль принадлежала как наличию вредной привычки, так и, вероятно, носительству рисковых полиморфных вариантов других генов (среди генов-кандидатов описаны гены $E P H X 1$ (микросомальной эпоксидгидролазы), GST (глутатион-S-трансферазы), $I L-6$ (интерлейкина-6), IREB2 (протеина 2, связывающего железозависимый элемент), $M M P 9$ (матриксной металлопротеиназы 9), $T G F-\beta$ (трансформирующего фактора роста- $\beta), I L 1 B$ (интерлейкина-1)) [16].

Сопоставление частот аллелей ОНП rs1137101 у пациентов с изолированным СОАГС $(46,2 \%$ для аллеля $A$ и $53,8 \%$ для $G$ ) и представителей других популяций согласно проекту «1000 геномов» (http://grch37. ensembl.org) не выявило статистически значимых раз- личий по отношению к европейской (EUR; 53,1\% для аллеля $A$ и $46,9 \%$ для аллеля $G ; \mathrm{p}=0,13)$ и южноазиатской (SAS; $46,2 \%$ для аллеля $A$ и $53,8 \%$ для аллеля $G$; $\mathrm{p}=0,44)$ популяциям, тогда как у представителей Восточной Азии регистрировались другие частоты (EAS; $13,1 \%$ для аллеля $A$ и $86,9 \%$ для аллеля $G ; \mathrm{p}<0,001$ ). Можно предположить, что характер генетических ассоциаций у жителей Красноярского края будет сходен с таковым у представителей европейской популяции.

Действительно, было показано, что носительство аллеля $G$ и гомозиготного генотипа $G G$ статистически значимо ассоциировано с формированием фенотипа 2 , но не 3 степени ожирения. Развитие ожирения 3 степени вследствие многофакторной природы заболевания может быть обусловлено как носительством полиморфных вариантов гена $L E P R(\mathrm{Q} 223 \mathrm{R}, \mathrm{K} 109 \mathrm{R}$ и K656N), так и мутациями других генов, ответственных за формирование ожирения (LEP, PCSK1, PPARG), а также влиянием факторов внешней среды, таких как образ жизни и особенности питания [17].

Резюмируя полученные данные, следует отметить, что среди жителей г. Красноярска исследование OHП Q223R гена $L E P R$ не может быть использовано в качестве генетического предиктора формирования СОАГС и, как следствие, ночной гипоксемии у пациентов с ХОБЛ. Тем не менее, поиск генетических маркёров, ответственных за предрасположенность к развитию СОАГС, должен быть продолжен.

\section{Заключение}

Показано, что носительство как полиморфного аллеля $G$, так и генотипа $G G$ не является фактором риска развития СОАГС у пациентов с ХОБЛ $(\mathrm{p}=0,92)$ и не ассоциировано со степенью тяжести обеих нозологий, но статистически значимо ассоциировано с формированием ожирения 2 степени $(\mathrm{p}<0,05)$. При этом наличие вредной привычки (курение) играет основную роль в формировании фенотипа ХОБЛ и существенно не влияет на развитие СОАГС. Полученные данные свидетельствуют о том, что у жителей Красноярского края исследование ОНП Q223R гена $L E P R$ не может быть использовано в качестве генетического предиктора формирования синдрома перекрёста.

\section{Список литературы}

1. Thornton A.T., Ruehland W.R., Rochford P. et al. AASM criteria for scoring respiratory events: interaction between apnea sensor and hypopnea definition. Sleep. 2012;35(3):425-432.

2. Stradling J.R., Crosby J.H. Predictors and prevalence of obstructive sleep apnoea and snoring in 1001 middle aged men. Thorax 1991; 46(2):85-90. 
3. Kuccukturk S., Yosunkaya S., Kuzu Okur H.K. et al. The Relationship between obstructive sleep apnea and Gln223Arg polymorphism in human leptin receptor gene. Eur J Biol. 2017;76(2):43-50.

4. Patel S.R. Shared genetic risk factors for obstructive sleep apnea and obesity. J Appl Physiol. 2005;99:1600-1606.

5. Панков Ю.А. Лептин и его медиаторы в регуляции жирового обмена. Ожирение и метаболизм. 2010;2:3-9.

6. Шнайдер Н.А., Петрова М.М., Демко И.В. и др. Промежуточные фенотипы синдрома обструктивного апноэ/гипопноэ сна. Неврология, нейропсихиатрия, психосоматика. 2016;8(4):81-85.

7. Полуэктов М.Г. Синдром обструктивного апноэ во сне: современные представления и роль. Ожирение и метаболизм. 2010;1:2-7.

8. Фадеева М.И., Савельева Л.В., Фадеев В.В. Синдром обструктивного апноэ сна в практике врача-эндокринолога. Ожирение и метаболизм. 2010;10:3-10.

9. Stanchina M.L., Welicky L.M., Donat W. et al. Impact of CPAP use and age on mortality in patients with combined COPD and obstructive sleep apnoea: the overlap syndrome. J Clin Sleep Med. 2013;9:767-772.

10. Бабак С.Л., Голубев Л.А., Горбунова М.В. Дыхательные расстройства в период сна у больных с хронической обструктивной болезнью легких. Хроническая обструктивная болезнь легких. М.: Атмосфера. 2008:502-512.

11. Шнайдер Н.А., Демко И.В., Алексеева О.В. и др. Фенотипические и генотипические факторы риска синдрома обструктивного апноэ/гипопноэ сна. Проблемы женского здоровья. 2015;10(2):55-64.

12. Алексеева О.В., Шнайдер Н.А., Демко И.В. и др. Клиническое наблюдение синдрома обструктивного апноэ сна у 60 -летнего мужчины с хронической обструктивной болезнью легких. Сибирское медицинское обозрение. 2017;1(103):70-73.

13. Popko K., Gorska E., Wasik M. et al. Frequency of distribution of leptin receptor gene polymorphism in obstructive sleep apnea patients. J Physiol Pharmacol. 2007;58(S5):551-561.

14. Li Z., Wu W., Gu L. et al. Lack of association variants of leptin and leptin receptor gene and OSAHS in Chinese Han population. 2016;14:37-46. DOI 10.1007/s41105-015-0022-X.

15. Van den Borst B., Souren N.Y.P., Loos R.J.F. et al. Genetics of maximally attained lung function: A role for leptin? Respir Med. 2012;106:235-242. doi:10.1016/j.rmed.2011.08.001

16. Xie Z-K., Huang Q-P., Huang J. et al. Association between the IL1B, IL1RN polymorphisms and COPD risk: A meta-analysis. Sci Rep. 2014;4:6202. DOI: 10.1038/srep06202

17. Snyder E.E., Walts B., Pérusse L. et al. The human obesity gene map: the 2003 update. Obes Res. 2004;12(3):369-439.

\section{References}

1. Thornton A.T., Ruehland W.R., Rochford P. et al. AASM criteria for scoring respiratory events: interaction between apnea sensor and hypopnea definition. Sleep. 2012;35(3):425-432.

2. Stradling J.R., Crosby J.H. Predictors and prevalence of obstructive sleep apnoea and snoring in 1001 middle aged men. Thorax 1991; 46(2): 85-90.

3. Kuccukturk S., Yosunkaya S., Kuzu Okur H.K. et al. The Relationship between obstructive sleep apnea and Gln223Arg polymorphism in human leptin receptor gene. Eur J Biol. 2017; 76(2):43-50.

4. Patel S.R. Shared genetic risk factors for obstructive sleep apnea and obesity. J Appl Physiol. 2005;99:1600-1606.

5. Pankov Yu.A. Leptin i yego mediatory v regulyatsii zhirovogo obmena [Leptin and its mediators in the regulation of fat metabolism]. Ozhireniye i metabolizm [Obesity and metabolism]. 2010; 2: 3-9(In Russ.)

6. Shnayder N.A., Petrova M.M., Demko I.V. et al. Promezhutochnyye fenotipy sindroma obstruktivnogo apnoe/gipopnoe sna [Intermediate phenotypes of obstructive sleep apnea / hypopnea syndrome]. Nevrologiya, neyropsikhiatriya, psikhosomatika [Neurology, neuropsychiatry, psychosomatics]. 2016; 8 (4): 81-85. (In Russ.)

7. Poluektov M.G. Sindrom obstruktivnogo apnoe vo sne: sovremennyye predstavleniya i rol' [Obstructive sleep apnea syndrome: current views and role]. Ozhireniye i metabolizm [Obesity and metabolism]. 2010; 1: 2-7. (In Russ.)

8. Fadeeva M.I., Savelyeva L.V., Fadeev V.V. Sindrom obstruktivnogo apnoe sna v praktike vracha-endokrinologa [Obstructive sleep apnea syndrome in the practice of an endocrinologist]. Ozhireniye i metabolism [Obesity and metabolism]. 2010; 10: 3-10 (In Russ.)

9. Stanchina M.L., Welicky L.M., Donat W. et al. Impact of CPAP use and age on mortality in patients with combined COPD and obstructive sleep apnoea: the overlap syndrome. J Clin Sleep Med. 2013;9:767-772.

10. Babak S.L., Golubev L.A., Gorbunova M.V. Dykhatel'nyye rasstroystva v period sna u bol'nykh s khronicheskoy obstruktivnoy bolezn'yu legkikh. Khronicheskaya obstruktivnaya bolezn' legkikh [Respiratory disorders during sleep in patients with chronic obstructive pulmonary disease. Chronic obstructive pulmonary disease]. M.: Atmosfera [M.: Atmosphere]. 2008: 502-512 (In Russ.)

11. Shnayder N.A., Demko I.V., Alekseeva O.V. et al. Fenotipicheskiye i genotipicheskiye faktory riska sindroma obstruktivnogo apnoe/gipopnoe sna [Phenotypic and genotypic risk factors for obstructive sleep apnea / hypopnea syndrome]. Problemy zhenskogo zdorov'ya [Problems of women health]. 2015; 10 (2): 55-64 (In Russ.)

12. Alekseeva O.V., Shnayder N.A., Demko I.V. et al. Klinicheskoye nablyudeniye sindroma obstruktivnogo apnoe sna u 60-letnego muzhchiny s khronicheskoy obstruktivnoy bo-lezn'yu legkikh [Clinical observation of obstructive sleep apnea in 60-year-old man with chronic obstructive pulmonary disease]. Sibirskoye meditsinskoye obozreniye [Siberian Medical Review]. 2017; 1 (103): 70-73. (In Russ.)

13. Popko K., Gorska E., Wasik M. et al. Frequency of distribution of leptin receptor gene polymorphism in obstructive sleep apnea patients. J Physiol Pharmacol. 2007;58(S5):551-561.

14. Li Z., Wu W., Gu L. et al. Lack of association variants of leptin and leptin receptor gene and OSAHS in Chinese Han population. 2016;14:37-46. DOI 10.1007/s41105-015-0022-x.

15. Van den Borst B., Souren N.Y.P., Loos R.J.F. et al. Genetics of maximally attained lung function: A role for leptin? Respir Med. 2012;106:235-242. doi:10.1016/j.rmed.2011.08.001

16. Xie Z-K., Huang Q-P., Huang J. et al. Association between the IL1B, IL1RN polymorphisms and COPD risk: A meta-analysis. Sci Rep. 2014;4:6202. DOI: 10.1038/srep06202

17. Snyder E.E., Walts B., Pérusse L. et al. The human obesity gene map: the 2003 update. Obes Res. 2004;12(3):369-439. 